\title{
Investigating the Rheological Properties of Crumb Rubber Modified Bitumen and its Correlation with Temperature Susceptibility
}

\author{
Nuha Salim Mashaan*, Mohamed Rehan Karim \\ Center for Transportation Research, Faculty of Engineering, \\ University of Malaya, 50603 Kuala Lumpur, Malaysia
}

Received: April 13, 2012; Revised: August 19, 2012

\begin{abstract}
There is substantial evidence on the advantages of using crumb rubber in enhancing conventional bitumen properties, gaining environmental protection and boosting industrial-economical benefits. Thus, the use of this ingenious additive in bitumen modification through sustainable technology is highly advocated.The main objective of this research is to investigate the effects of different blending conditions (of time and temperature) and various crumb rubber contents on the properties of bitumen binders. Testing was conducted using the Dynamic shear rheometer (DSR) test and softening point test. The results showed that differing crumb rubber contents and blending temperature have significant effects on modified binder properties whereas the blending time showed an insignificant effect. Higher blending temperature and crumb rubber content were found to influence the interaction of bitumen-rubber blends and also increased the swelling rate of rubber particles, resulting in an increase in complex shear modulus $\left(\mathrm{G}^{*}\right)$, storage modulus ( $\left.\mathrm{G}^{\prime}\right)$, loss modulus (G') and softening point as well as a decrease in phase angle $(\delta)$. Thus, the modified bitumen became less susceptible to deformation after stress removals. The study also presented a considerable relationship between rheological parameters $\left(G^{*}, G^{\prime}, G^{\prime}\right.$ and $\delta$ ) and softening point in terms of predicting physical-mechanical properties regardless of blending conditions. Thus, in terms of elasticity for the softening point data, the storage modulus and phase angle were found to be good indicators of binder elasticity. When softening point is made available, a prediction about binder ability to recover its original shape after stress removals can be done.
\end{abstract}

Keywords: modified bitumen, CRM, rheology, blending conditions

\section{Introduction}

An immense problem affecting environmental pollution is the increase of waste tyre vehicles. In an attempt to decrease the magnitude of this issue, crumb rubber modifier (CRM) obtained from waste tyre rubber has gained interest in asphalt modification. Generally, the rheological and performance properties of rubberised bitumen binder are influenced by blending conditions and crumb rubber contents $^{1-3}$. Bitumen is a dark black semisolid material, obtained from the atmospheric and vacuum distillation of crude oil during petroleum refining. Being a thermoplastic visco-elastic adhesive, it is used for road and highway pavement engineering, primarily because of its good cementing power and waterproof properties ${ }^{4}$.

Bitumen as a colloidal system consists of high molecular asphaltene/resin micelles diffused in an oily medium of lower molecular weight, constituted by naphthenic aromatics and saturated compounds. The micelles are mainly a composite of asphaltene and resins acting as stabilisers to the mixture. The asphaltene and resins may be related in an open network yet they can be disintegrated as discrete particles by varying the amounts of resin, asphaltene and oils in percentages ${ }^{4}$.

*e-mail: nuhaasim@siswa.um.edu.my
Studies $^{5}$ show that the rheological properties of the binder are strongly related to bitumen colloidal behaviour. Also, bitumen binder possesses a strong temperature dependence on rheological properties organised by the interaction of individual constitution (asphaltene, resins, aromatics, saturates). Additionally, the study reported that an increase in one of these constitutions would change the structure and rheological behaviour of bitumen. Thus, bitumen with high asphaltene/resins ratio, led to a network structure with more rigidity and elasticity (low in phase angle and high in complex shear modulus), unlike the case of bitumen with high resins/asphaltene ratio which in contrast led to high viscous behaviour.

Rheology is the study of deformation and flow of materials. It is the science knowledge that is related to all aspects of deformation of material under the influence of external stresses. Bitumen behaves in a unique manner depending upon both the load applied and the rate of loading. Temperature additionally is a factor that could be correlated with the rate of loading. At elevated temperatures, or slow rates of loading, bitumen becomes a viscous material. At decreased temperatures or higher rates of loading, bitumen becomes a highly elastic material. However, at intermediate 
temperatures, bitumen has two different characteristics; i.e. an elastic solid and a viscous fluid ${ }^{6}$. The study of bitumen rheology is an important phenomenon to characterise the dynamic mechanical behaviour of binders ${ }^{7,8}$. Previous research has shown that the major mechanism of the bitumen - rubber interaction is the swelling of the rubber particles because of the absorption of the light fractions oil into the rubber particles and stiffening of the residual binder $^{9-12}$.

According to a study ${ }^{13}$, the higher the crumb rubber content is, the higher viscosity at $135^{\circ} \mathrm{C}$ could improve the rutting properties. It was also observed that the increased crumb rubber amount produced rubberised bitumen with higher viscosity and lower resilience ${ }^{14,15}$. However, for optimum crumb rubber content; crumb rubber size and asphalt binder need to be determined. It is believed that a physic-chemical interaction occurs between the bitumen and the crumb rubber which alters the effective size and physical properties of the rubber particle, thus influencing pavement performance ${ }^{16}$. Higher crumb rubber content also led to improved physical and rheological properties of modified bitumen binder through better rutting resistance as well as increased its elastic recovery ${ }^{17-19}$.

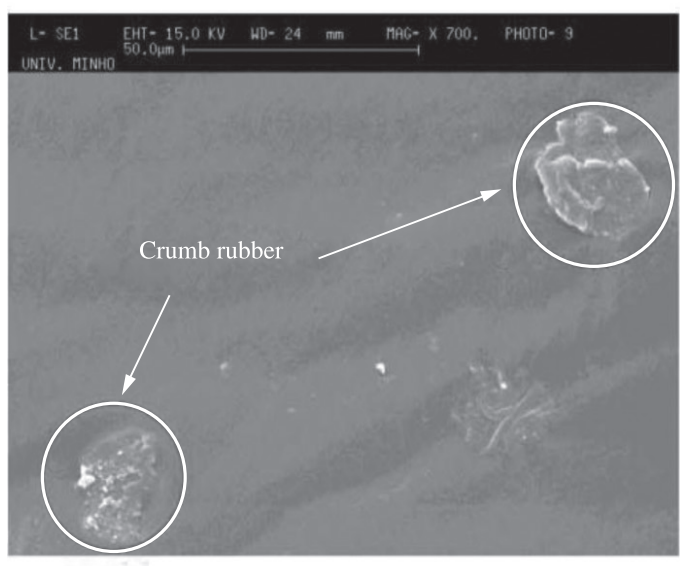

30 minutes

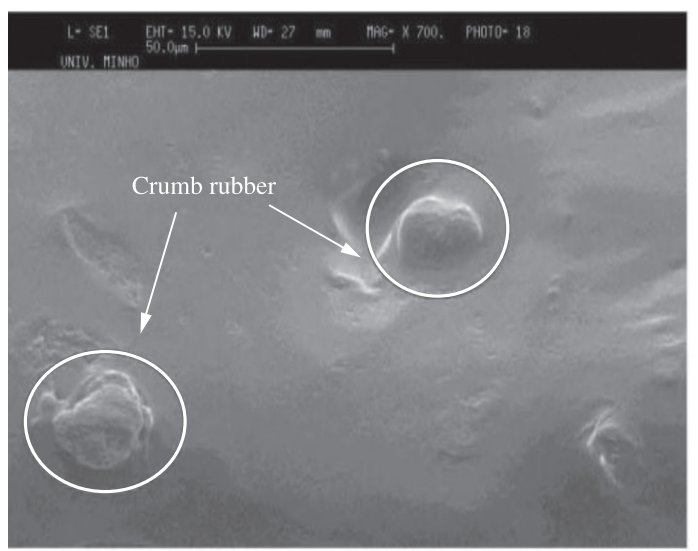

60 minutes
Investigations ${ }^{18}$ which focused on the effect of crumb rubber concentration on physical and mechanical properties of modified binder used rutting parameter $\left(\mathrm{G}^{*} / \mathrm{sin}(\delta)\right)$, ductility and elastic recovery to evaluate the modified binder properties. The results indicated that the higher crumb rubber concentration has the potential to resist permanent deformation (rutting).

A research study ${ }^{20}$, conducted on the effect of combination factors of CRM percentage and mixing time on rheological properties of rubberised bitumen showed that the main factor that influenced the elastic recovery of rubberised bitumen is the higher content of crumb rubber. The mixing time did not show a significant effect on binder recovery after deformation. Various investigations ${ }^{21,22}$ showed that the blending time has no significant effect on the selection of the optimal binder content or on the compaction of the mixture.

According to another investigation ${ }^{23}$ conducted on the effect of blending conditions (time and temperature) on penetration, softening point and resilience modulus; stated that there was no significant effect using three different blending time (45, 60 and 90 minutes) on modified binder properties although there was a tendency for blending time to become constant between 60 and 90 minutes. Figure 1 shows the results of ${ }^{23}$ the effect of blending time

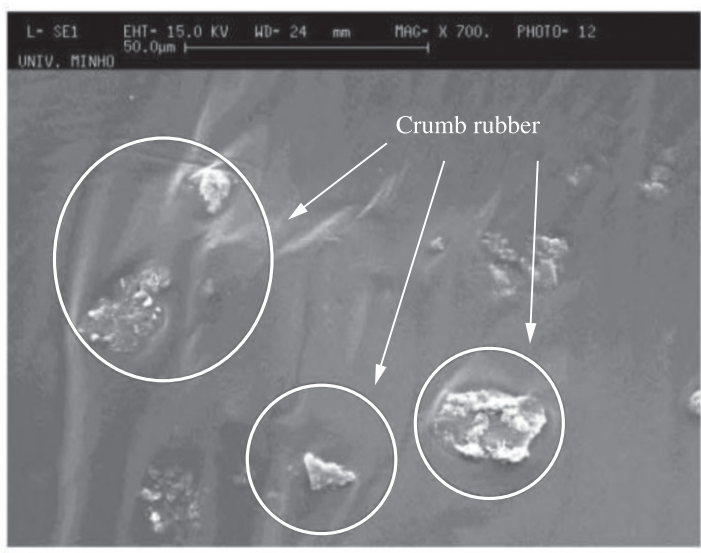

45 minutes

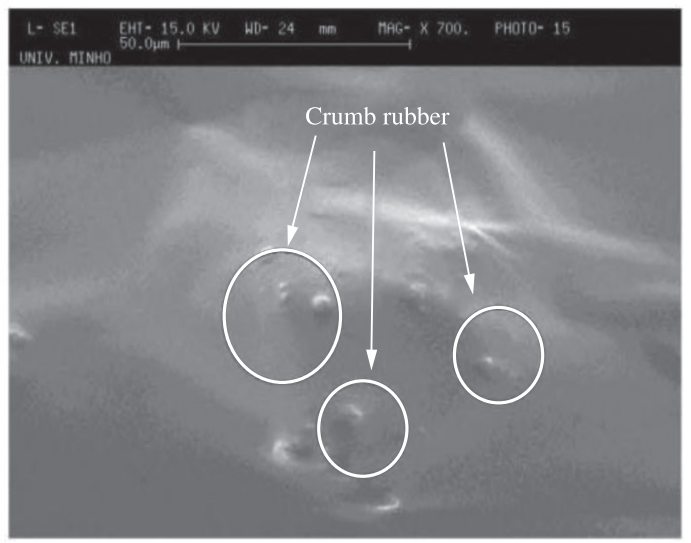

90 minutes

Figure 1. Micrographs of the finished rubberised bitumen for different blending time ${ }^{23}$. 
on rubberised bitumen process, from the micrographs of the finished rubberised bitumen binder. It is evident that relatively huge amounts of rubber are present in 30 and 45 minutes of reaction time. In 60 and 90 minutes of reaction time, the bitumen-rubber structures showed that the system is compatible. In 90 minutes of reaction time, the crumb rubber is fully incorporated in the bitumen binder.

However, a study ${ }^{1}$ showed that longer blending time has a significant effect on the binder properties, resulting in an increase in viscosity and rutting resistance. In recent years, researches on applications of rubberised bitumen binders have reported many advantages. These advantages include improved bitumen resistance to rutting due to high viscosity ${ }^{14,15}$, high softening point ${ }^{17}$, better rutting resistance ${ }^{24,25}$, improved bitumen resistance to surface initiated cracks and reduction of fatigue cracking ${ }^{26-28}$, reduction of temperature susceptibility and improved durability $^{29,30}$ as well as reduction in road pavement maintenance costs ${ }^{14}$.

The current study aims to investigate the effect of adding crumb tyre rubber as an additive to bitumen, using the wet process. Two laboratory tests were conducted to evaluate the performance of physical-mechanical properties at high temperature of rubberised asphalt binder. Tested results were compared and analysed statistically. The two way variance analysis (ANOVA) was performed to determine the significance at a certain confidence limit. The primary objective of this study was to investigate the influence of blending condition of (time and temperature) and crumb rubber content on the rheological properties of rubberised bitumen. The second objective was to determine the correlation between rheological parameters $\left(\mathrm{G}^{*}\right.$, G', G' and $\delta$ ) and softening point in term of predicting physical-mechanical properties.

\section{Material and Methods}

In this study bituminous binder of $80 / 100$ penetration grade was used. Table 1 shows the characteristics of the base bitumen. Table 2 shows the penetration test ${ }^{31}$, softening point (Ring \& Ball) test ${ }^{32}$, Brookfield viscosity test $^{33}$, ductility test ${ }^{34}$, elastic recovery test ${ }^{35}$ and dynamic shear rheometer (DSR) test ${ }^{36}$. These tests were which were conducted to evaluate the engineering properties of bitumen binder reinforced with CRM. Table 2 illustrates the improvement in the crumb rubber modified bitumen's physical and rheological properties, through an increase in the viscosity, softening point, ductility, elastic recovery and stiffness parameter. This phenomenon could be explained by the absorption of rubber particles by lighter fraction oil of bitumen, leading to swelling of rubber particles during the blending process.

For the purpose of maintaining consistency of the CRM throughout the entire study, one batch of crumb rubber obtained from one local source was solely used. In this study, fine crumb rubber size 30 \# $(0.6 \mathrm{~mm})$ was selected in order to reduce segregation ${ }^{14}$. The chemical composition of crumb rubber is illustrated in Table 3.

A propeller mixer was used to prepare the rubberised bitumen and the wet process (mixing the bitumen with rubber prior to mixing the aggregate) was utilised. Binder mixing was conducted at the velocity speed of $200 \mathrm{rpm}$. Two different blending temperatures $\left(160\right.$ and $180{ }^{\circ} \mathrm{C}$ ) and blending times (30 and 60 minutes) and five different percentages of crumb rubber by binder weight $(0 \%, 4 \%$, $8 \%, 12 \%, 16 \%$ and $20 \%$ ) were selected.

The binder tests used in this study were Dynamic Shear Rheometer (DSR) and softening point (Ring \& Ball) test. According to the specification test, softening point is the temperature at which the bitumen reaches a particular degree of softening. This is tested using a ring and ball apparatus. According to ASTM D36 ${ }^{[32]}$, bitumen is a visco-elastic materials without specifically defined melting points. It slowly becomes softer and less viscous as temperature is elevated. Thus, softening point has to be determined by an arbitrary and closely defined method for results to be reproduced.

Dynamic shear rheometer (DSR) was used to measure and determine the rheological properties of the bitumen binder at $76{ }^{\circ} \mathrm{C}$. Specification testing was performed at a test frequency of $10 \mathrm{rad} / \mathrm{s}$ which is equivalent to the car speed of $90 \mathrm{~km} / \mathrm{h}$. Test specimens of $1 \mathrm{~mm}$ thick by $25 \mathrm{~mm}$ in diameter were formed between parallel metal plates. DSR results included parameters of complex shear modulus $\left(G^{*}\right)$, storage modulus $\left(G^{\prime}\right)$, loss modulus ( $\left.G^{\prime \prime}\right)$ and phase angle $(\delta)$. The formula to calculate the $\mathrm{G}^{*}, \mathrm{G}^{\prime}$, G' as well as $\delta$ in Equations 1, 2, 3 and 4, respectively is demonstrated below:

$\mathrm{G}^{*}=(\tau / \gamma)$

Table 1. Properties of virgin bitumen grade $80 / 100$ penetration.

\begin{tabular}{ccc}
\hline Test properties & Standard test & Test result \\
\hline Viscosity @ $135^{\circ} \mathrm{C}(\mathrm{pas})$ & ASTM D4402 & 0.65 \\
$\mathrm{G}^{*} / \sin \delta @ 64{ }^{\circ} \mathrm{C}(\mathrm{kpa})$ & ASTM D4 & 1.35 \\
Ductility @ $25^{\circ} \mathrm{C}$ & ASTM D113 & 100 \\
Softening point @ $25^{\circ} \mathrm{C}$ & ASTM D36 & 47 \\
Penetration @ $25^{\circ} \mathrm{C}$ & ASTM D5 & 88 \\
\hline
\end{tabular}

Table 2. Physical and rheological properties of rubberised bitumen.

\begin{tabular}{ccc}
\hline Test properties & Standard test & Test result \\
\hline Viscosity @135 ${ }^{\circ} \mathrm{C}($ pas $)$ & ASTM D4402 & 0.85 \\
G*/sin $\delta @ 64{ }^{\circ} \mathrm{C}(\mathrm{kpa})$ & ASTM D4 & 1.89 \\
Ductility @ $25^{\circ} \mathrm{C}$ & ASTM D113 & 91 \\
Softening point @ $25^{\circ} \mathrm{C}$ & ASTM D36 & 49 \\
Penetration@ $25^{\circ} \mathrm{C}$ & ASTM D5 & 76 \\
Elastic recovery @ $25^{\circ} \mathrm{C}$ & ASTM D6084 & $85 \%$ \\
\hline
\end{tabular}

Table 3. Chemical composition of crumb rubber.

\begin{tabular}{cc}
\hline Major rubber components & Test data $(\%)$ \\
\hline Acetone extract & 10.0 \\
Rubber hydrocarbon & 25.0 \\
Carbon black content & 30.0 \\
Natural rubber content & 31.0 \\
Ash content & 4.0 \\
\hline
\end{tabular}


$\mathrm{G}^{\prime}=\cos (\delta)(\tau / \gamma)$

$G^{\prime \prime}=\sin (\delta)(\tau / \gamma)$

$\delta=\mathrm{G} / \mathrm{G}^{\prime}$

where $\mathrm{G}^{*}$ is the complex shear modulus, $\tau$ is the shear stress, $\gamma$ is the shear strain, $G^{\prime}$ is the storage modulus, $G$ " is the loss modulus, and $\delta$ is the phase angle.

\section{Analysis of Results and Discussion}

\subsection{Analysis of $G^{*}$ results at $76^{\circ} \mathrm{C}$}

Figures 2 and 3 show an increase in complex shear modulus $\mathrm{G}^{*}$ as the rubber content is increased in the bituminous specimens. The results showed that there were a significant difference in the $\mathrm{G}^{*}$ at various blending temperature. A higher blending temperature of rubberised bitumen binder led to better $\mathrm{G}^{*}$ results for samples of $4 \%$ to $20 \%$ rubber content by about $4.5 \%$ to $44 \%$ at 30 minutes and $180{ }^{\circ} \mathrm{C}$.

This increase was possibly due to the amount of asphaltene in the virgin bitumen which enhanced the viscous flow of the modified bitumen sample during the interaction process. The crumb rubber content also exhibited a strong

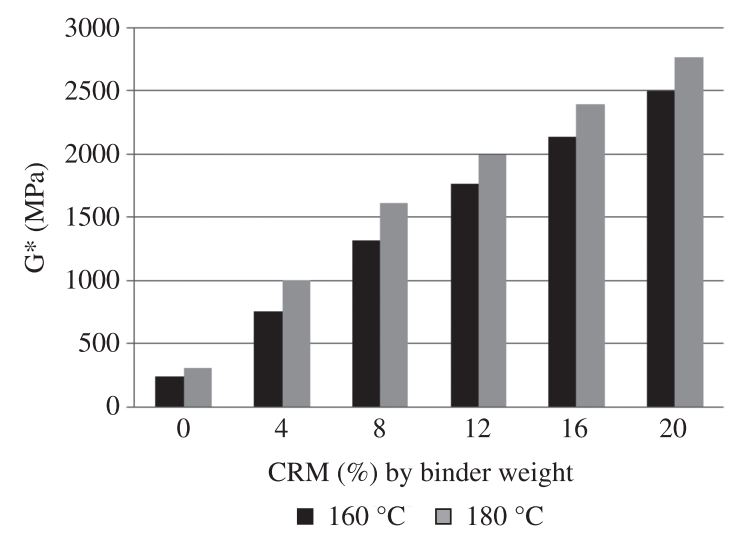

Figure 2. G* results vs. blending temperature at 30 minutes.

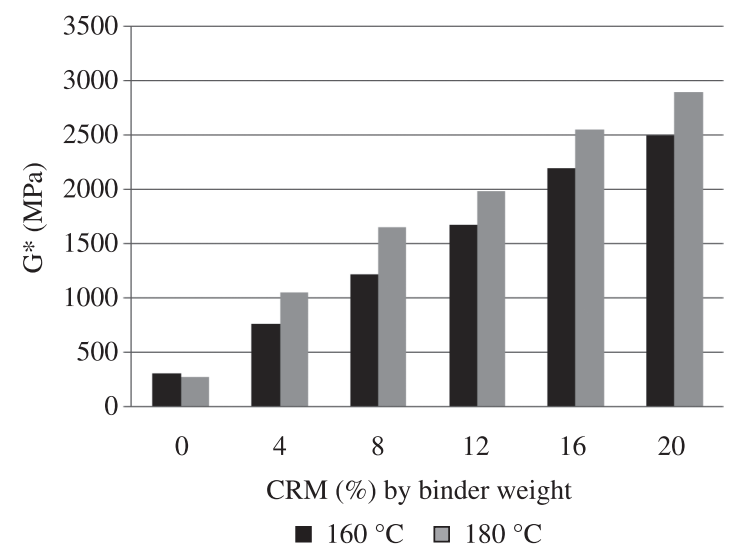

Figure 3. $G^{*}$ vs. blending temperature at 60 minutes. effect on complex shear modulus improvement by increasing the stiffness of CRM bitumen binders. The variation in complex shear modulus due to varied blending times did not show any significant changes for virgin bitumen samples and rubberised bitumen, at varied mixing temperatures of $160^{\circ} \mathrm{C}$ and $180^{\circ} \mathrm{C}$, respectively as shown in Figures 4 and 5 .

\subsection{Analysis of phase angle results at $76{ }^{\circ} \mathrm{C}$}

The phase angle $(\delta)$ represents the transition from viscous to elastic solid behaviours of bitumen binders. The higher values of phase angles corresponded to binders that became more viscous, also with lower values and more elastic in nature. In general, this reflects a trade-off between high and low temperature performances of bitumen binders $^{37}$. The phase angle is the shift between the applied stress and the resultant strain. It can be used to understand the visco-elastic properties of the material, and also signifies the mechanical loss. In a purely elastic response, the phase angle will be zero, whereas a purely viscous response will be indicated by a phase angle of $90^{\circ}$. Figure $6^{[38]}$ presents the transition behaviour of phase angle for a visco-elastic material.

Figures 7 and 8 display the effect of blending temperature and rubber content on the phase angle at $76^{\circ} \mathrm{C}$. The blending temperature affected the properties of rubberised binder in terms of phase angle. Also, the increase

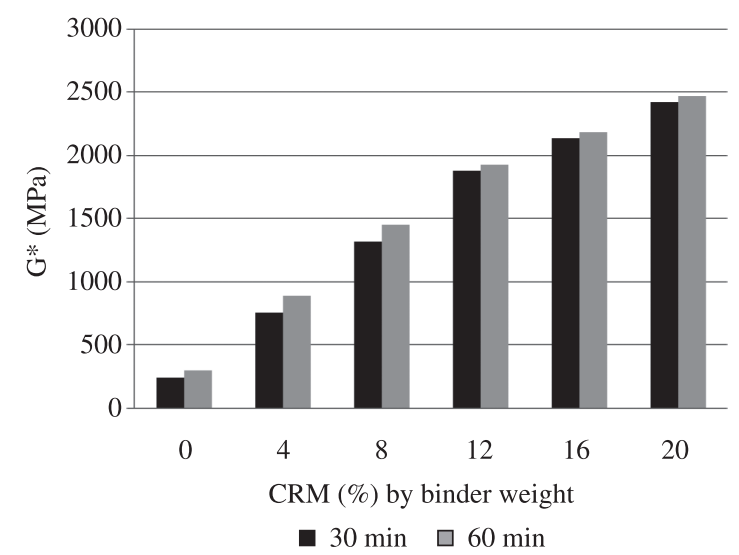

Figure 4. $\mathrm{G}^{*}$ results vs. blending time at $160^{\circ} \mathrm{C}$.

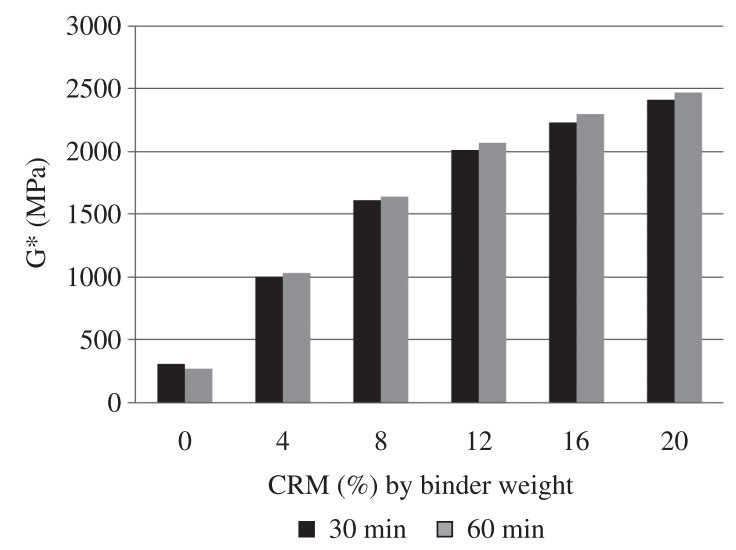

Figure 5. $\mathrm{G}^{*}$ results vs. blending time at $180^{\circ} \mathrm{C}$. 
in crumb rubber content led to a decrease of the phase angle of rubberised binder.

Figures 9 and 10 show the effects of blending time on the phase angle at $76^{\circ} \mathrm{C}$. It is evident that blending time does not affect the properties of rubberised binder in terms of phase angle. Thus, the primary reduction in the phase angle could be attributed to the effect of rubber content. Enhancing the rubber content led to the increase of black carbon reacting with natural rubber, which corresponded to the elastic part of the crumb rubber chemistry. It was observed that the blending time of 30 minutes might not have been adequate to allow complete reaction between the crumb rubber and bitumen binder ${ }^{21}$.

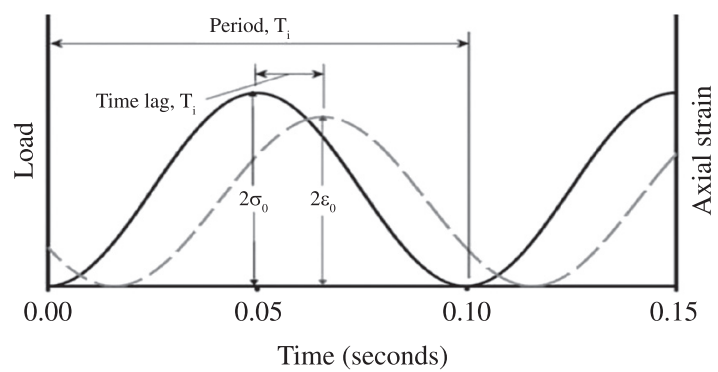

Figure 6. The transition behaviour of phase angle for a visco-elastic material

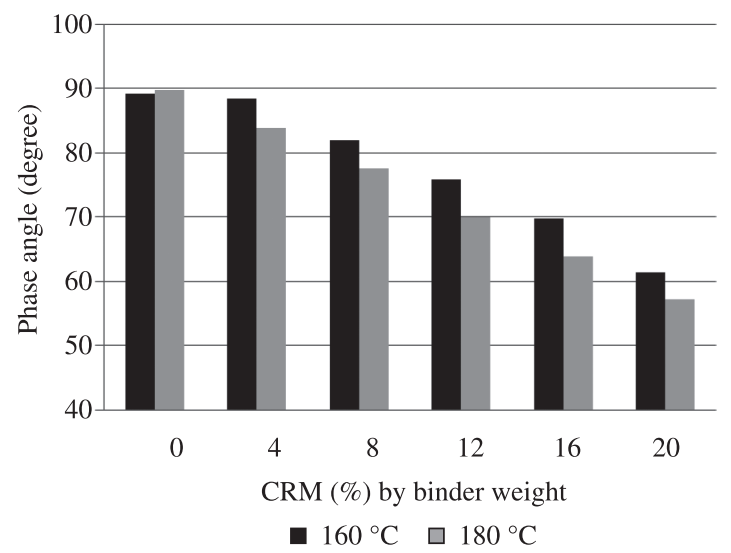

Figure 7. Phase angle $\delta$ vs. blending temperature at 30 minutes.

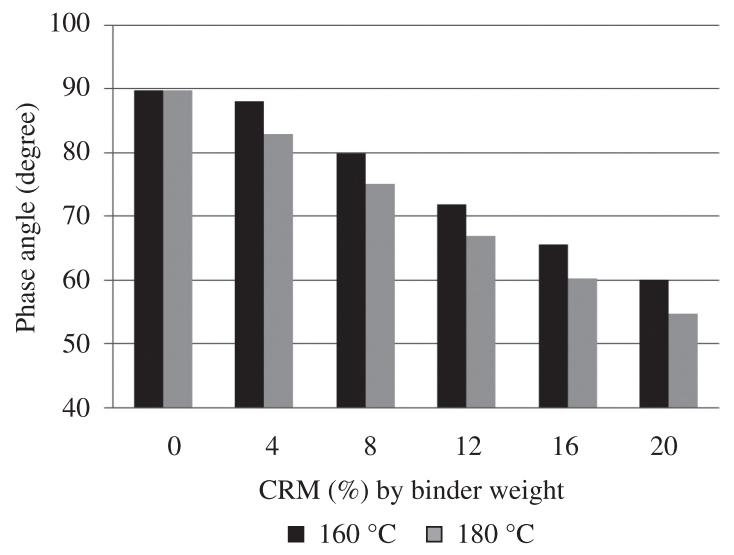

Figure 8. Phase angle $\delta$ vs. blending temperature at 60 minutes.

\subsection{Analysis of storage modulus and loss modulus results at $76{ }^{\circ} \mathrm{C}$}

During the curing process and construction of asphalt binders and aggregate mixes, one of the most important design requirements considered was the elastic deformation of bitumen binder, including its viscous flow behaviour. The virgin bitumen is considered for its variation from viscous to elasticity depending on loading stresses and varying temperatures. To substantiate further the various behaviours resulting from the viscous to elastic binder, the two components storage G' and loss modulus G" were analysed. The scientific results of the main mechanism of modified and unmodified binders under different blending conditions were determined by using varying crumb rubber contents.

The results of the storage modulus are shown in Figures 11-14, while the results of loss modulus are presented in Figures 15-18. The results show that storage modulus G' and loss modulus G' appeared to have increased as the crumb rubber content is increased.

In this current study, adding crumb rubber to the virgin bitumen increased both storage and loss modulus over the range of blending conditions. Given that the crumb rubber might dissolve and disperse into the bitumen, the mechanical properties of the modified binder could

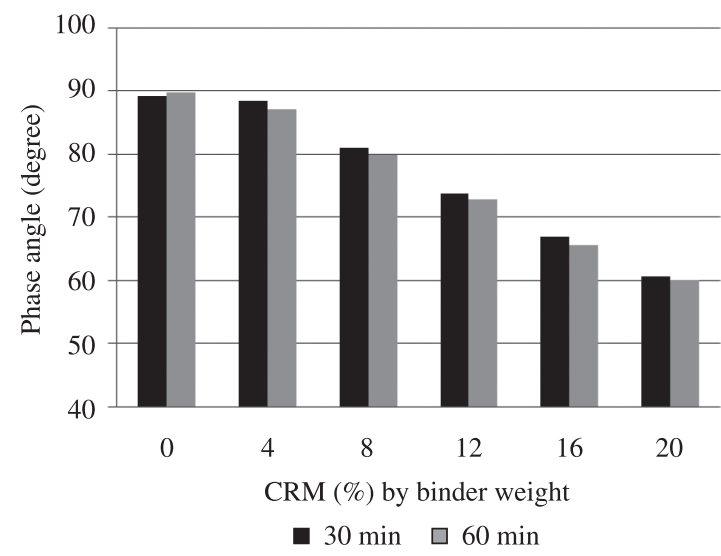

Figure 9. Phase angle $\delta$ results vs. blending time at $160{ }^{\circ} \mathrm{C}$.

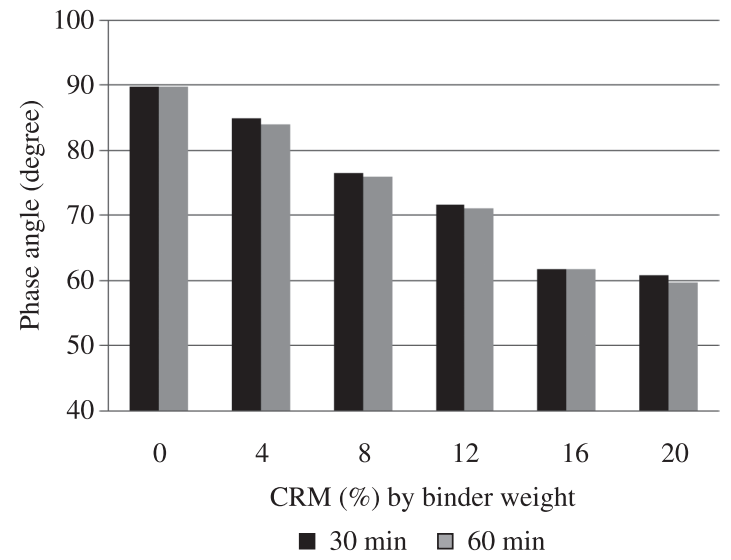

Figure 10. Phase angle $\delta$ results vs. blending time at $180{ }^{\circ} \mathrm{C}$. 


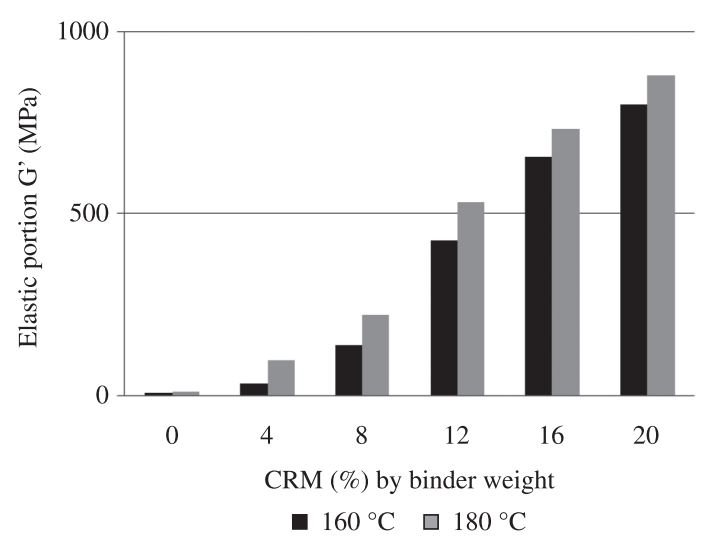

Figure 11. Elastic modulus vs. blending temperature at 30 minutes.

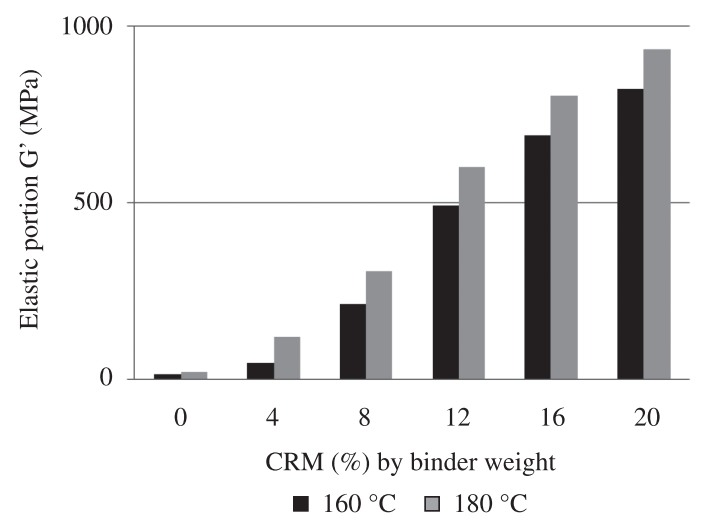

Figure 12. Elastic modulus vs. blending temperature at 60 minutes.

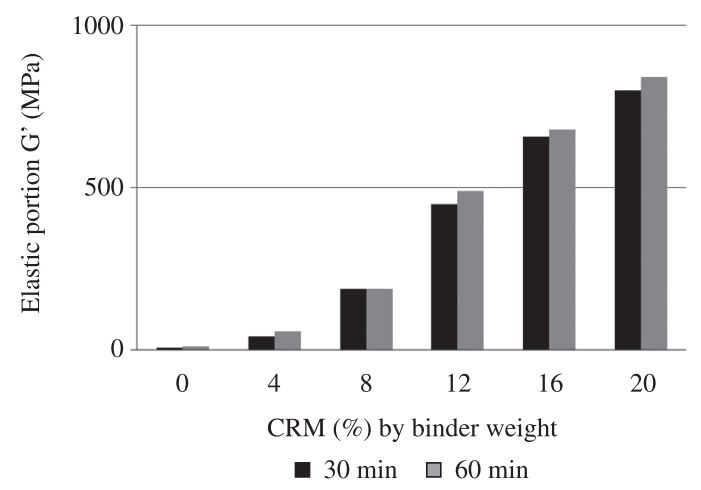

Figure 13. Elastic modulus results vs. blending time at $160^{\circ} \mathrm{C}$.

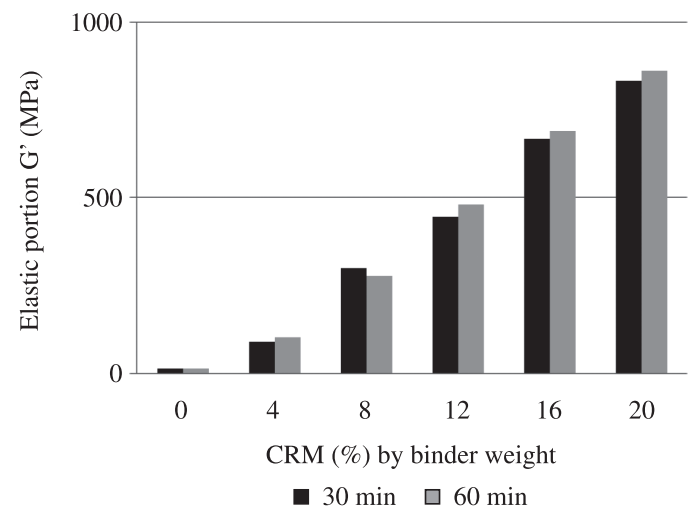

Figure 14. Elastic modulus results vs. blending time at $180{ }^{\circ} \mathrm{C}$. be enhanced. Another reason would be the physical and chemical properties of both bitumen and crumb rubber. These properties are generally affected during the interaction processes because rubber particle dimensions are reduced, due to breakdown or depolymerisation of rubber particles digested in asphalt binders ${ }^{39}$.

In Figures 11-14, the effect of blending time on storage modulus G' (elastic portion) and loss modulus G' (viscous portion) showed insignificant differences between the blending times of 30 and 60 minutes for all CRM contents. However, the blending temperature showed obvious significant effect on both $G$ ' and G' as shown in Figures 15-18. The increases reflect that blending temperature was the primary control factor of the blending conditions for the rubberised bitumen binder. These results of the storage modulus may also enhance the elastic response of the modified binders. The elasticity and recovery of the modified binders improved after they were subjected to shear stress and strain deformation. The increase in storage modulus and loss modulus could have resulted from the oxidation processes of bitumen fractions. The interaction processes of blending temperature and bending time could have dominated the visco-elastic behaviour of the rubberised bitumen binder. The bitumen binder became softer at $76^{\circ} \mathrm{C}$. When these interaction condition processes were sufficient, the binder might show predominant elastic properties.

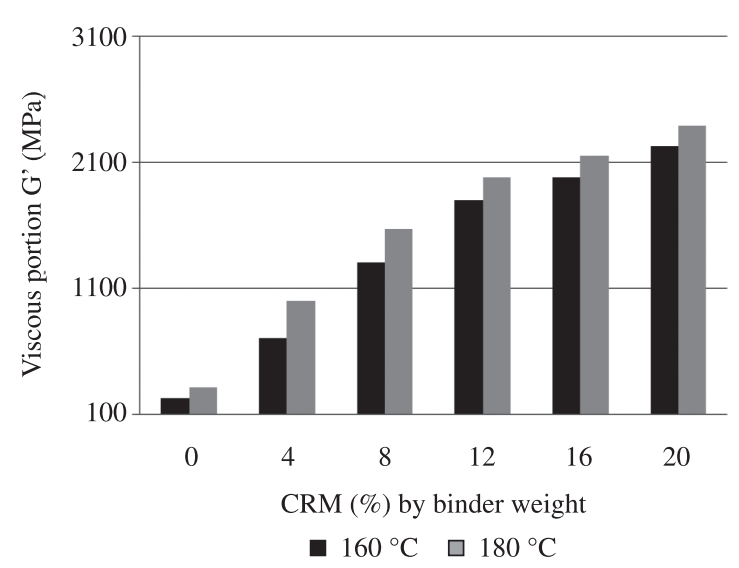

Figure 15. Viscous modulus vs. blending temperature at 30 minutes.

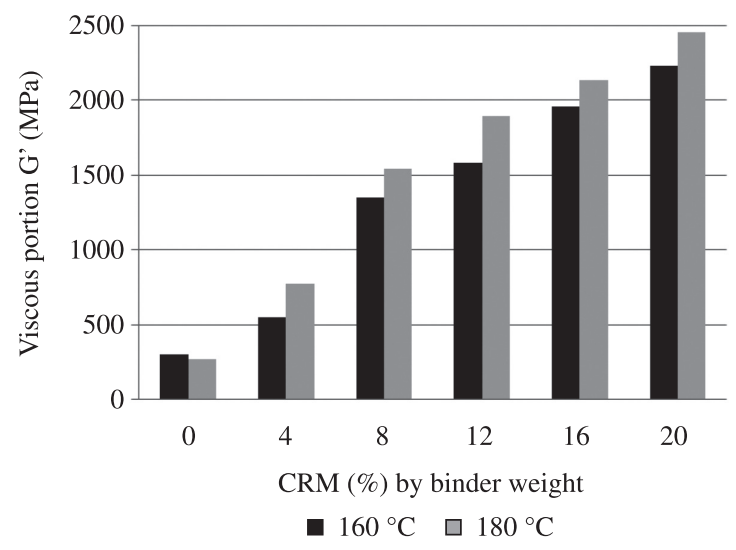

Figure 16. Viscous modulus vs. blending temperature at 60 minutes. 
Storage modulus (elastic portion) was higher than loss modulus (viscous portion); this phenomenon was proven by the increase in phase angle values. An ideal binder is sufficiently stiff at high temperatures in order to withstand permanent deformation (rutting) and sufficiently soft at low temperatures in order to avoid excessive thermal stresses leading to fatigue. The results of this study indicated that the crumb rubber-modified binder manifest visco-elastic behaviours, with the binder exhibiting better relaxation upon applied stress on the asphalt rubber. In summary, the results have confirmed that rubber-modified binders could become less susceptible to temperature changes as rubber content is increased. The results further confirmed improvements in asphalt performance properties at high service temperatures.

\subsection{Analysis of softening point results}

The variation in softening point due to varied blending temperature and CRM content showed significant results for all modified samples, while it displayed insignificant influence on the unmodified bitumen as shown in Figures 19 and 20. The increase in blending temperature led to an increase in rubber mass through the interaction and swelling of the rubber into the bitumen during the blending process. This in turn led to the increase in the softening point values of rubberised bitumen samples. The increase of rubber content in the mix could be co-related to the increase in

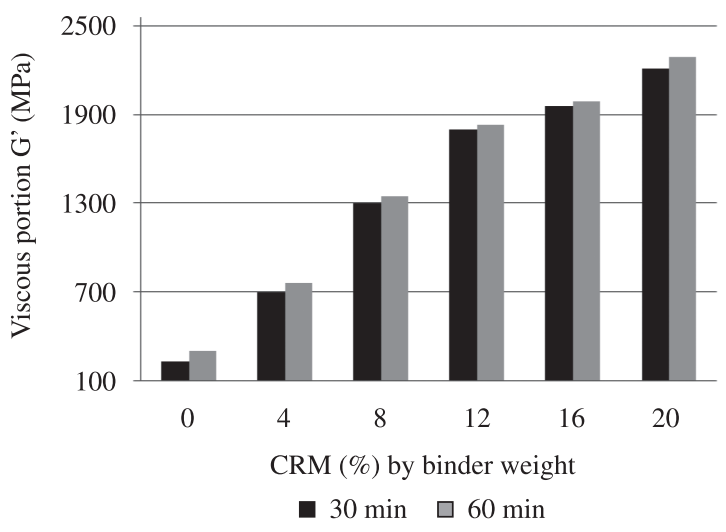

Figure 17. Viscous modulus results vs. blending time at $160^{\circ} \mathrm{C}$.

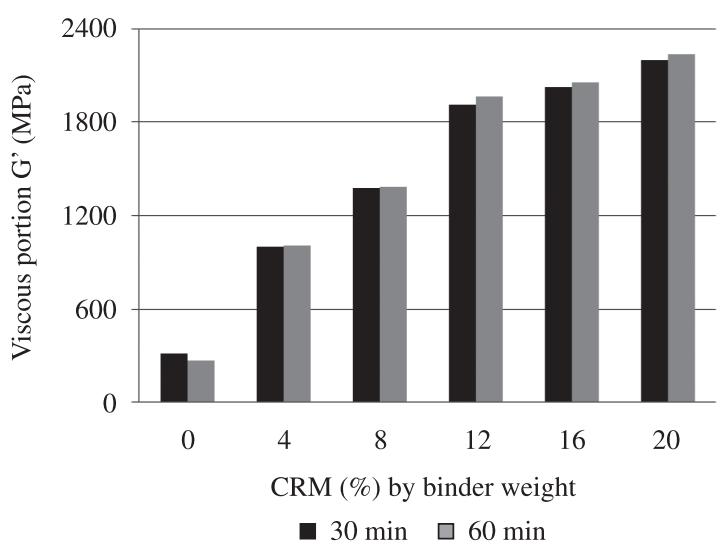

Figure 18. Viscous modulus results vs. blending time at $180^{\circ} \mathrm{C}$. the asphaltene/resins ratio which probably enhanced the stiffening properties, making the modified binder less susceptible to temperature changes.

As illustrated in Figures 21 and 22, the results showed that there was no significant difference in the softening point results at blending times 30 and 60 minutes, respectively, when tested at different temperatures. This indicates that the increase in softening point values was highly affected by crumb rubber content rather than the blending time. According to Liu et al. ${ }^{14}$, the main factor in the increase in

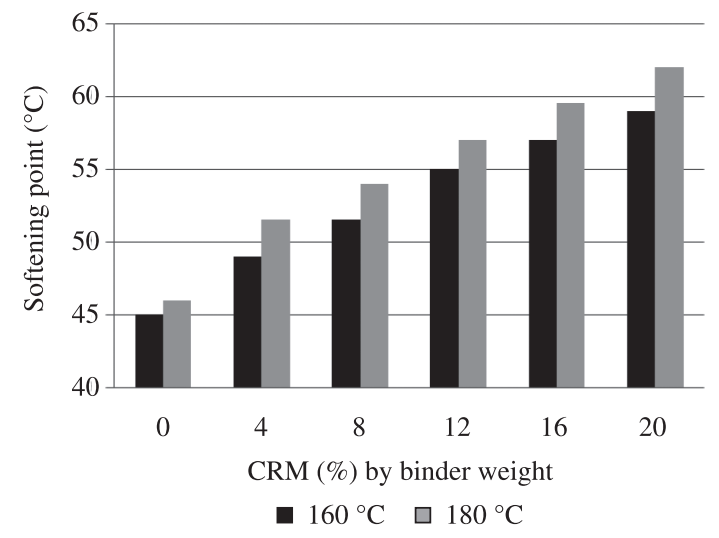

Figure 19. Softening point vs. blending temperature at 30 minutes.

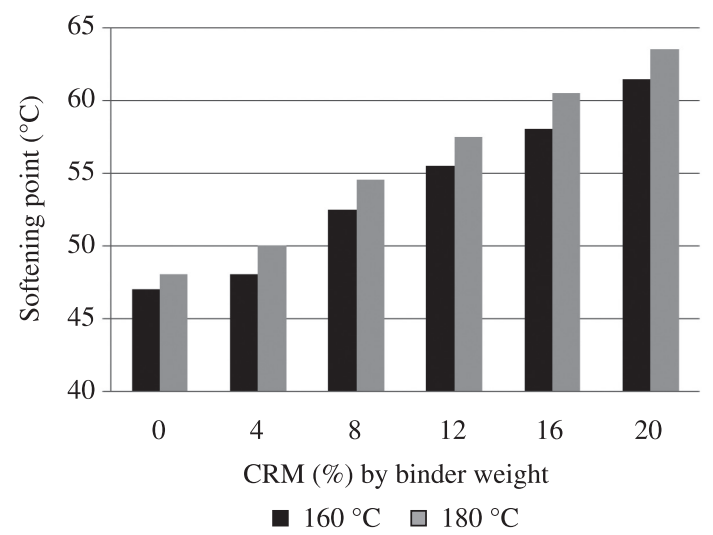

Figure 20. Softening point vs. blending temperature at 60 minutes.

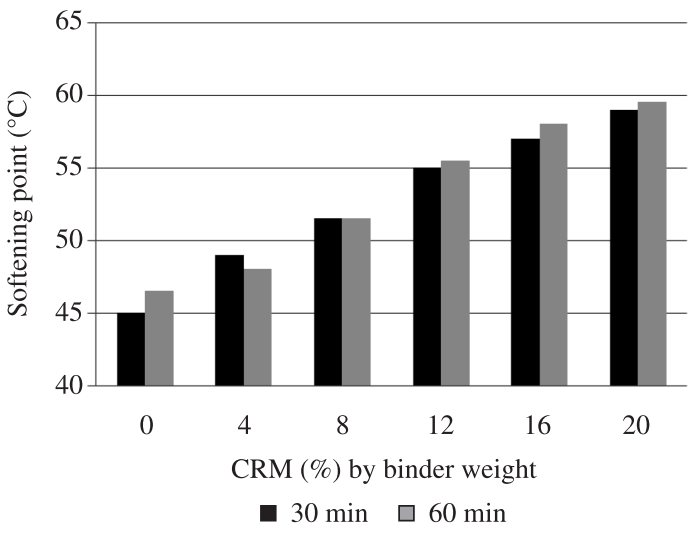

Figure 21. Softening point results vs. blending time at $160{ }^{\circ} \mathrm{C}$. 
softening point can be attributed to crumb rubber content, regardless of type and size. The increase in softening point led to a stiff binder that has the ability to enhance its recovery after elastic deformation.

\section{Analysis of Variance (ANOVA)}

Analysis of Variances (ANOVA) is a statistical method that is used for assessing relationships and differences among the means of two or several data sets. It is a guide for determining whether or not differences in a set of counts or measurements are most likely due to the modern chance variation. In this study, Two- way ANOVA was performed

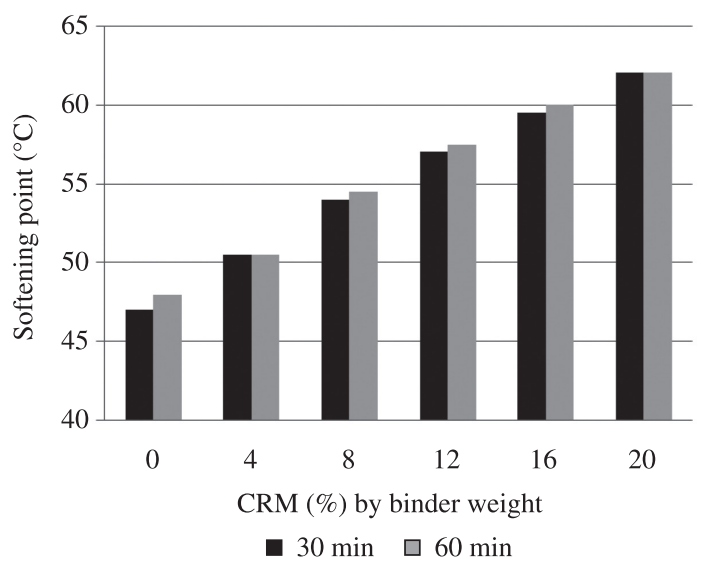

Figure 22. Softening point results vs. blending time at $180{ }^{\circ} \mathrm{C}$. using Two Factors replication: performing an analysis of variance between two or more data sets. The significant level of the data sets is determined by evaluating the F- ratio and comparing it to the F- critical value for the samples. If the F- ratio (F-Statistic) is larger than F- critical, then the variation between the groups is statistically significant. The level of significance $(\alpha)$ used in this research was 0.05 .

As displayed in Table 4, in the case of variance analysis of CRM content, the value of F (4.002457) is greater compared to the value of F-critical (2.456281) and also, the $\mathrm{P}$ value is smaller than the assumed value $(\alpha)$ of 0.05 . In the case of variance analysis of mixing temperature, the the value of $F(4.907769)$ is greater compared to the value of F-critical (3.54557) and also, the P value (0.0049) is smaller than the assumed value $(\alpha)$. In the case of variance analysis of mixing time, the the value of $\mathrm{F}$ (2.086463) is greater compared to the value of F-critical (3.554511) and also, the $P$ value $(0.299)$ is higher than the assumed value $(\alpha)$. It can be concluded that the effect of CRM content and mixing temperature on complex shear modulus is significant, whereas the mixing time has no significance on $\mathrm{G}^{*}$ at 30 and 60 minutes, respectively.

Tables 5-8 present the analysis of storage modulus, loss modulus, phase angle and softening point, respectively. The $F$ values seem to be larger than the values of F-critical, while the P-values are smaller than $(\alpha)$. Therefore, it can be similarly concluded that the impact of CRM content and mixing temperature on the G', G', $\delta$ and softening point are also significant. In addition, mixing time has no significance on G', G', $\delta$ and softening point. Therefore, the bitumen

Table 4. ANOVA analysis of complex shear modulus $\mathrm{G}^{*}$.

\begin{tabular}{ccccccl}
\hline Source of variation & SS & df & MS & F & P-value & F critical \\
\hline CRM content & 2684.304 & 5 & 298.256 & 4.002457 & 0.00594 & 2.456281 \\
Mixing temp. & 39033.8 & 2 & 19516.9 & 4.907769 & 0.0049431 & 3.54557 \\
Mixing time & 44739.97 & 2 & 22369.99 & 2.086463 & 0.299758 & 3.554511 \\
Error & 1341.328 & 18 & 74.51822 & & & \\
Total & 87799.438 & 27 & & & & \\
\hline
\end{tabular}

Table 5. ANOVA analysis of storage modulus G'.

\begin{tabular}{cccccll}
\hline Source of variation & SS & df & MS & F & P-value & F critical \\
\hline CRM content & 2315.957 & 5 & 275.326 & 3.890247 & 0.00794 & 2.456281 \\
Mixing temp. & 49033.8 & 2 & 19516.9 & 4.007769 & 0.0049431 & 3.54557 \\
Mixing time & 44739.97 & 2 & 21369.09 & 2.000462 & 0.99758 & 3.554557 \\
Error & 1341.328 & 18 & 74.51822 & & & \\
Total & 97431.055 & 27 & & & & \\
\hline
\end{tabular}

Table 6. ANOVA analysis of loss modulus G".

\begin{tabular}{ccccccc}
\hline Source of Variation & SS & df & MS & F & P-value & F critical \\
\hline CRM content & 6700177 & 5 & 478584.1 & 4.060362 & 0.000784 \\
Mixing temp. & 49033.8 & 2 & 19516.9 & 4.007769 & 0.0049431 \\
Mixing time & 30060.2 & 2 & 1503045 & 1.520119 & 0.88223 \\
Error & 2635180 & 18 & 94113.56 & & \\
Total & 9414451 & 27 & & & \\
\hline
\end{tabular}


Table 7. ANOVA analysis of phase angle $\delta$.

\begin{tabular}{ccccccc}
\hline Source of variation & SS & df & MS & F & P-value & F critical \\
\hline CRM content & 2030.779 & 5 & 225.6421 & 5.837168 & 0.007323 & 2.456281 \\
Mixing temp. & 43168.69 & 2 & 21584.34 & 4.053613 & 0.000015 & 3.554557 \\
Mixing time & 44739.97 & 2 & 22369.99 & 2.086463 & 0.299758 & 3.554557 \\
Error & 2635180 & 18 & 94113.56 & & & \\
Total & 2725119.439 & 27 & & & & \\
\hline
\end{tabular}

Table 8. ANOVA analysis of softening point.

\begin{tabular}{ccccccc}
\hline Source of variation & SS & Df & MS & F & P-value & F critical \\
\hline CRM content & 276.0973 & 5 & 30.67748 & 4.01787 & 0.005826 & 2.456281 \\
Mixing temp. & 21578.7 & 2 & 10789.35 & 6.81007 & 0.00221 & 3.554557 \\
Mixing time & 20530 & 2 & 10265 & 1.420796 & 0.2455 & 3.554557 \\
Error & 2635180 & 18 & 94113.56 & & & \\
Total & 2677564.7 & 27 & & & & \\
\hline
\end{tabular}

binder of $20 \% \mathrm{CRM}$ prepared at $180{ }^{\circ} \mathrm{C}$ and 30 minutes has the best performance properties at high temperature.

\section{Rheological Properties as a Function of Softening Point}

To investigate the relationship between rheological properties and softening point, DSR parameters (G*, G', G' and $\delta$ ) were determined at corresponding temperatures to the binder and plotted versus the softening point as shown in Figures 23-26, respectively.

As presented in Figures 23-25 the results showed an increase in $\mathrm{G}^{*}, \mathrm{G}^{\prime}, \mathrm{G}^{\prime}$ ' as the softening point was increased. The results demonstrated a linear relationship between $\mathrm{G}^{*}, \mathrm{G}^{\prime}, \mathrm{G}^{\prime}$, and the softening point with strong correlation coefficient value ( $\mathrm{R}^{2}$ higher than 0.92$)$. Thus, an increase in $\mathrm{G}^{*}, \mathrm{G}^{\prime}, \mathrm{G}^{\prime}$ ' is accompanied by an increase in softening point as well. Also, it is observed that the higher the CRM content is, the higher $\mathrm{G}^{*}, \mathrm{G}^{\prime}, \mathrm{G}^{\prime}$ ' and softening point are. Therefore, the modified binder will be stiffer and less susceptible to rutting deformation.

As illustrated in Figure 26, the results showed a decrease in phase angle $(\delta)$ as softening point increased. The decrease in phase angle $\delta$ indicates that the modified binder will be more elastic and less viscous which results in better resistance to flow deformation at high temperature through life service. The results also showed a considerable relationship between phase angle and softening point with correlation coefficient $\left(\mathrm{R}^{2}=0.95\right)$.

\section{Comparison of Findings with Previous Studies}

Higher crumb rubber content led to improved physical and rheological properties of modified bitumen binder through higher softening point, an increase in viscosity and better rutting resistance ${ }^{1,13-19}$. In the current study, crumb rubber content is highly significant in the elevation of the softening point leading to less susceptible temperatures of

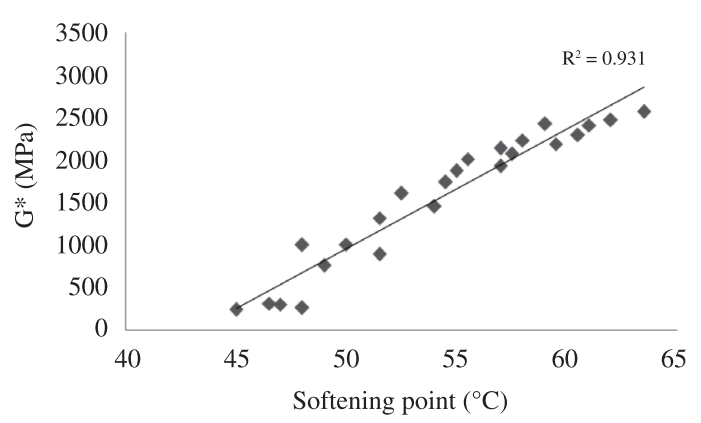

Figure 23. Complex shear modulus and softening point relationship.

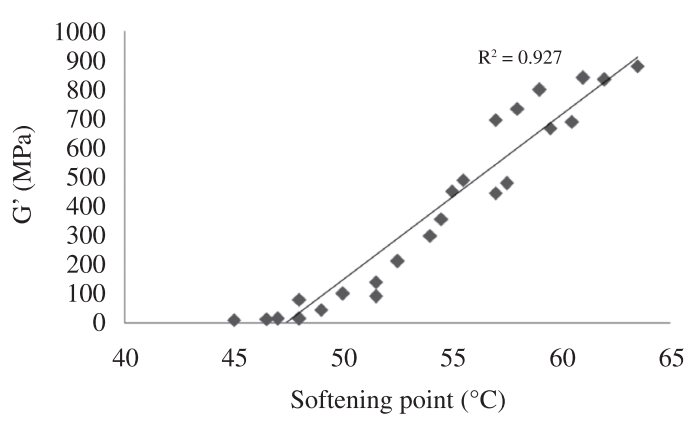

Figure 24. Storage modulus (elastic portion) and softening point relationship.

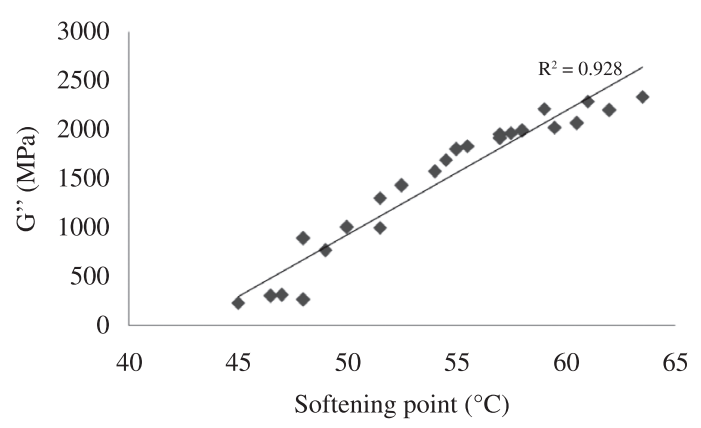

Figure 25. Loss modulus (viscous portion) and softening point relationship. 


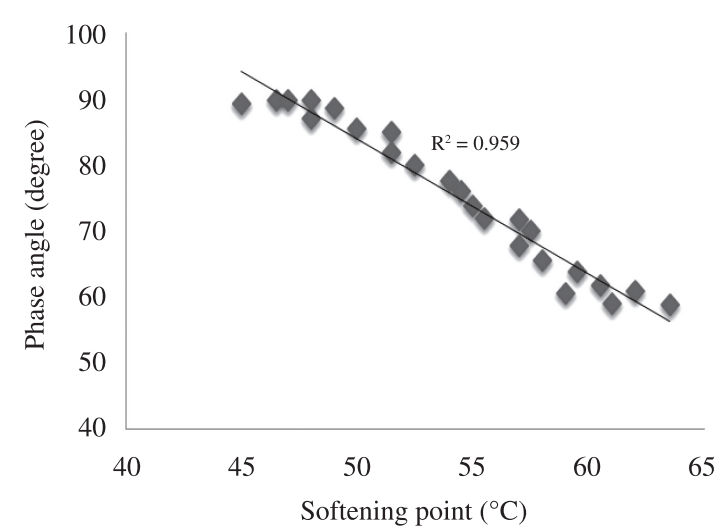

Figure 26. Phase angle and softening point relationship.

modified binders. Also, higher CRM content has an obvious effect in increasing the rheological parameters of $\mathrm{G}^{*}, \mathrm{G}^{\prime}$, G" and decrease in phase angle. With different unmodified and modified bitumen binders, the range of CRM content obtained in the current study is found to be comparable with earlier investigations.

Several investigations showed that the blending time ranging from 15-90 minutes had no significant effect on the physical and rheological properties of modified and unmodified bitumen binder ${ }^{20-23}$. In the current study, the blending time (30 minutes and 60 minutes) showed no effect on modified bitumen properties including physical and reheological properties. Also, it is rather interesting to observe that the result of blending time is not in tandem with the finding ${ }^{1}$ that longer blending time significantly affected the modified binder properties but has no effect on the control binder (unmodified). As mentioned earlier, the significance of time and temperature conditions will vary based on several limits related to binder properties and additive characteristics as well. Additionally, because of the high mixing temperatures, the bitumen binder during the process may results in primary aging, mainly due to oxidation of maltene compounds, and polymer degradation. Current experimental results are found to be comparable with the values in published literature. However differences could be related to several variation limits which included bitumen binder properties (penetration grade, type, source, asphaltene/resins ratio) and polymer characteristics include (type, chemical composition, surface texture, practical size and agitation conditions).

With respect to blending temperature, there have been so few investigations conducted on the effect of blending temperature. The higher blending temperature $\left(150-240^{\circ} \mathrm{C}\right)$ has a significant effect on rutting resistance, viscosity and high failure temperature of modified binders ${ }^{1,23}$. The current study presented an obvious effect of blending temperature ( 160 and $180^{\circ} \mathrm{C}$ ) on modified binder elasticity, stiffness and temperature susceptibility by increasing the complex shear modulus, elastic modulus and softening point. In summary, the current results are found to be comparable with findings of previous literatures.

\section{Conclusion and Further Recommendations}

Based on laboratory investigations and results obtained from this study, the following conclusions from binder tests on both unmodified and rubberised bitumen demonstrated that:

- The increase in blending temperature corresponded to the increase in complex shear modulus G*, G', G' and softening point, and a decrease in phase angle;

- The increase in blending time showed an insignificant difference in the case of 30 and 60 minutes. There was an extremely slight effect on $\mathrm{G}^{*}, \mathrm{G}^{\prime}, \mathrm{G}^{\prime}$ ' and $\delta$ at $76{ }^{\circ} \mathrm{C}$ as well as softening point at $25{ }^{\circ} \mathrm{C}$ for all modified bitumen samples;

- It is evident that rubber crumb content played a primary role in significantly influencing the performance and rheological properties of rubberised bitumen binders. Also, CRM can enhance the performance properties of asphalt pavement resistance against deformation during construction and road services;

- The study presented a considerable relationship between rheological parameters $\left(\mathrm{G}^{*}, \mathrm{G}^{\prime}, \mathrm{G}^{\prime}\right.$ ' and $\delta$ ) and softening point in terms of predicting physical-mechanical properties regardless of blending conditions. In offering a prediction about binder elasticity and the ability to recover its original shape after stress removals when softening point is made available and vice versa;

- There is also a need to test more binder sources, different blending times (90, 200, 240 and 390 minutes) and blending temperatures (190, 200, 250 and $300{ }^{\circ} \mathrm{C}$ ) and various rubber particle sizes (40 and 80 mesh); and

- The conclusions of this work show that the use of softer bitumen develops binders with an improved behaviour in road pavements. However, these conclusions are only obtained through binder characterisation. Therefore, these results should be further validated by carrying out tests in bituminous mixtures and by evaluating pavement trials constructed with rubberised bitumen. 


\section{References}

1. Jeong KD, Lee SJ, Amirkhanian SN and Kim KW. Interaction effect of crumb rubber modified asphalt binder. Construction and Building Materials. 2010; 24:824-831. http://dx.doi. org/10.1016/j.conbuildmat.2009.10.024

2. Tayfur S, Ozen $\mathrm{H}$ and Aksoy A. Investigation of rutting performance of asphalt mixtures containing polymer modifiers. Construction and Building Materials. 2007; 21:328-337. http:// dx.doi.org/10.1016/j.conbuildmat.2005.08.014

3. Aflaki S and Memarzadeh M. Using two-way ANOVA and hypothesis test in evaluating crumb rubber modification (CRM) agitation effects on rheological properties of bitumen. Construction and Building Materials. 2011; 25:2094-210. http://dx.doi.org/10.1016/j.conbuildmat.2010.11.028

4. Rozeveld SJ, Shin E, Bhurke A, France L and Drzal L. Network morphology of straight and polymer modified asphalt cements. Microscopy Research and Technique. 1997; 38:529-543. http:// dx.doi.org/10.1002/(SICI)1097-0029(19970901)

5. Loeber L, Muller G, Morel J and Sutton O. Bitumen in colloid science: a chemical, structure and rheological approach. Fuel. 1998; 77(13):1443-1450. http://dx.doi.org/10.1016/ S0016-2361(98)00054-4

6. Van der Poel C. A general system describing the viscoelastic properties of bitumen and its relation to routine test data. Journal of Applied Chemistry. 1954; 4:221-236. http://dx.doi. org/10.1002/jctb.5010040501

7. Fernandes MRS, Forte MMC and Leite LFM. Rheological Evaluation of Polymer-Modified Asphalt Binders. Materials Research. 2008; 11( 3):381-386. http://dx.doi.org/10.1590/ S1516-14392008000300024

8. Lougheed TJ and Papagiannakis AT. Viscosity characteristics of rubber-modified asphalt. Journal of Materials in Civil Engineering. 1996; 8(3):153-156. http://dx.doi. org/10.10612F(ASCE)0899-1561(1996)83A3(153)

9. Shen J, Amirkhanian S N, Xiao F and Tang B. Influence of surface area and size of crumb rubber on high temperature properties of crumb rubber and modified binders. Construction and Building Materials. 2009; 23:304-310. http://dx.doi. org/10.1016/j.conbuildmat.2007.12.005

10. Airey GD, Rahman MM and Collop AC. Absorption of bitumen into crumb rubber using the basket drainage method. International Journal of Pavement Engineering. 2003; 4(2):105-119. http:// dx.doi.org/10.1080/1029843032000158879

11. Abdelrahman MA and Carpenter SH. Mechanism of interaction of asphalt cement with crumb rubber modifier. Transportation Research Record. 1999; 1661:106-113. http://dx.doi. org/10.3141/1661-15

12. Shen J and Amirkhanian SN. The influence of crumb rubber modifier (CRM) microstructure on the high temperature properties of CRM binder. International Journal of Pavement Engineering. 2005; 6(4):265-271. http://clemson.edu/ces/arts/ low-res-gpav-6-4-137316-265-271.pdf.

13. Lee SJ, Akisetty CK and Amirkhanian SN. The effect of crumb rubber modifier (CRM) on the performance properties of rubberized binder in HMA pavement. Construction and Building Material. 2008; 22:1368-1376. http://dx.doi. org/10.1016/j.conbuildmat.2007.04.010

14. Liu S, Cao W, Fang J and Shang S. Variance analysis and performance evaluation of different crumb rubber modified (CRM) asphalt. Construction and Building Materials. 2009; 23:2701-2708. http://dx.doi.org/10.1016/j. conbuildmat.2008.12.009
15. Thodesen C, Shatanawi K and Amerkhanian S. Effect of crumb rubber characteristics on crumb rubber modified (CRM) binder viscosity. Construction and Building Materials. 2009; 23:295-303. http://dx.doi.org/10.1016/j. conbuildmat.2007.12.007

16. Huang SC. Rubber concentration on rheology of aged asphalt binders. Journal of Materials in Civil Engineering. 2008; 20(3):221-229. http://dx.doi.org/10.1061/ (ASCE)0899-1561(2008)20:3(221)

17. Nejad FM, Aghajani P, Modarres A and Firoozifar H. Investigating the properties of crumb rubber modified bitumen using classic and SHRP testing methods. Construction and Building Materials. 2012; 26:481-489. http://dx.doi. org/10.1016/j.conbuildmat.2011.06.048

18. Mashaan NS, Ali AH, Karim MR and Abdelaziz M. Effect of crumb rubber concentration on the physical and rheological properties of rubberised bitumen binders. International Journal of Physical Science. 2011; 6(4):684-690. http://dx.doi. org/10.5897/IJPS11.113

19. Yildrim Y. Polymer modified asphalt binder. Construction and Building Materials. 2007; 21:66-72. http://dx.doi. org/10.1016/j.conbuildmat.2005.07.007

20. Mashaan NS, Ali AH, Karim MR and Abdelaziz M. Effect of blending time and crumb rubber content on properties of crumb rubber modified asphalt binder. International Journal of Physical Science. 2011; 6(9):2189-2193. http://dx.doi. org/10.5897/IJPS11.446

21. Moreno F, Rubio MC and Martinez-Echevarria MJ. Analysis of digestion time and the crumb rubber percentage in dry-process crumb rubber modified hot bituminous mixes. Construction and Building Materials. 2011; 25:2323-2334. http://dx.doi. org/10.1016/j.conbuildmat.2010.11.029

22. Putman BJ, Thompson JU and Amirkhanian SN. High temperature properties of crumb rubber modified binders. In: Proceedings of the Mairepav $4^{\text {th }}$ International Symposium: Maintenance and Rehabilitation of Pavements and Technological Control; 2005; Belfast, Northern Ireland. Belfast; 2005. p. 1-9. Available from: <http://www.clemson.edu/ces/arts/ MairepavHighTemperaturePropertiesofCRMBinders.pdf>

23. Paulo AAP and Jorge CP. Laboratory optimization of continuous blend asphalt rubber. In: Proceedings of 3rd European Pavement and Asset Management EPAM; 2008; Coimbra. Coimbra; 2008. p. 1-12. Available from: $<$ http://rodoviasverdes. ufsc.br/files/2010/03/LABORATORY-OPTIMIZATION-OFCONTINUOUS-BLEND-ASPHALT-RUBBER.pdf $>$.

24. Fontes LPTL, Trichês G, Pais JC and Pereira PAA. Evaluating permanent deformation in asphalt rubber mixtures. Construction and Building Materials. 2010; 24:1193-1200. http://dx.doi. org/10.1016/j.conbuildmat.2009.12.021

25. Wong CC and Wong WG. Effect of crumb rubber modifiers on high temperature susceptibility of wearing course mixtures. Construction and Building Materials. 2007; 21:1741-1745. http://dx.doi.org/10.1016/j.conbuildmat.2006.05.020

26. Celik ON and Atis CD. Compatibility of hot bituminous mixtures made with crumb rubber-modified binders. Construction and Building Materials. 2008; 22:1143-1147. http://dx.doi.org/10.1016/j.conbuildmat.2007.02.005

27. Arabani M, Mirabdolazimi SM and Sasani AR. The effect of waste tire thread mesh on the dynamic behaviour of asphalt mixtures. Construction and Building Materials. 2010; 24:1060-1068. http://dx.doi.org/10.1016/j. conbuildmat.2009.11.011

28. Xiao F, Zhao PEW and Amirkhanian SN. Fatigue behavior of rubberized asphalt concrete mixtures containing 
warm asphalt additives. Construction and Building Materials. 2009; 23:3144-3151. http://dx.doi.org/10.1016/j. conbuildmat.2009.06.036

29. Lee SJ, Amirkhanian SN and Kwon SZ. The effects of compaction temperature on CRM mixtures made with the SGC and the Marshall compactor. Construction and Building Materials. 2008 ; 22:1122-1128. http://dx.doi.org/10.1016/j. conbuildmat.2007.03.003

30. Partl MN, Pasquini E, Canestrari F and Virgili A. Analysis of water and thermal sensitivity of open graded asphalt rubber mixtures. Construction and Building Materials. 2010; 24:283-291. http:// dx.doi.org/10.1016/j.conbuildmat.2009.08.041

31. American Society for Testing and Materials - ASTM. ASTM D5: Standard Test Method for Penetration of Bituminous Materials. Easton: ASTM; 1997. vol. 04.03.

32. American Society for Testing and Materials - ASTM. ASTM $D$ 36: Standard Test Method for Softening Point of Bitumen (Ring - and - Ball Apparatus). Easton: ASTM; 2006. vol. 04.04.

33. American Society for Testing and Materials - ASTM. ASTM D4402: Standard Test Method for Viscosity Determinations of Unfilled Asphalts Using the Brookfield Thermosel Apparatus. Easton: ASTM; 2006. vol. 04.04.
34. American Society for Testing and Materials - ASTM. ASTM D113: Standard Test Method for Ductility of Bituminous Materials. Easton: ASTM; 2000. vol. 04.03.

35. American Society for Testing and Materials - ASTM. ASTM D 6084: Standard Test Method for Elastic Recovery of Bituminous Materials by Ductilometer. Easton: ASTM; 2006. vol. 04.03.

36. American Society for Testing and Materials - ASTM. ASTM D-4: Proposal P246 Determining the Rheological Properties of Asphalt binder for specification Purposes Using a Dynamic Shear Rheometer. Easton: ASTM; 2000. vol. 04.03.

37. Widyatmoko I and Elliott R. Characteristics of elastomeric and plastomeric binders in contact with natural asphalts. Construction and Building Materials. 2008; 22:239-249. http:// dx.doi.org/10.1016/j.conbuildmat.2005.12.025

38. Kumar SA and Veeraragavan A. Dynamic mechanical characterization of asphalt concrete mixes with modified asphalt binders. Materials Science and Engineering A. 2011; 528:6445-6454. http://dx.doi.org/10.1016/j. msea.2011.05.008

39. Xiao F, Ameirkhanian SN and Putman, BJ. Laboratory investigation of dimensional changes of crumb rubber reacting with asphalt binder. In: Proceeding Asphalt Rubber 2006 Conference; 2006; Palms Spring, California. Palms Spring; 2006. 